\title{
CULTURA INSTITUCIONAL: ASPECTOS Y ESTRATEGIAS A TRABAJAR
}

\author{
*Mag. Ruth E. Cruz Cárdenas
}

\section{Introducción}

Antes de abordar el tema, queremos poner el énfasis en la necesidad de entender que cuando estamos preocupados por la gestión, cuando deseamos actualizarla y mejorarla, cuando queremos innovar a través de ella, estamos iniciando un proceso que no se acaba en la incorporación de conocimientos, de técnicas, de un léxico determinado, de algunas acciones, en el marco de ciertos enfoques o concepciones acerca del centro educativo.

Se trata de comprender nuestra acción en el marco de un paradigma diferente al que ha sido dominante hasta el momento. Paradigma que ha sido en el cual nos hemos educado, como escolares, y en los centros de formación docente. A nuestra historia profesional y personal está integrada una racionalidad, una lógica que se sustenta en nuestras vivencias y valores, en nuestras creencias y prioridades. Es preciso construir un referente que oriente nuestro pensamiento y nuestra acción, que promueva una gestión distinta: por ahí debiera ir nuestro mayor esfuerzo.

Por eso es necesario situarnos en un nuevo paradigma, en una racionalidad, en una lógica distinta, que es preciso construir para cambiar realmente. Como ha expresado Aguerrondo, las acciones innovadoras son cambios realmente, cuando están orientadas e impactan en los aspectos estructurales. En este proceso de cambio, nuestro esfuerzo se orienta a modificar, en primer lugar, nuestro concepto de institución.

\section{La idea de institución}

Concebimos a la institución como un escenario de interacción social. No reconocemos a la organización, aspecto más visible de una institución, como tradicionalmente se ha hecho, como un ser vivo, como un instrumento, como una máquina. La institución no es un sistema acabado una vez estatuido, no es un modelo absoluto, sino que la institución es un "constructo": es una construcción permanente a cargo de los individuos que la integran, los actores, entendida así en el marco de una racionalidad relativa. La institución es un producto, en el que los individuos cuentan, pesan fundamentalmente, reconociéndoles el poder que naturalmente tienen, como seres pensantes y activos, con voluntad, sentimientos, emociones, creencias y convicciones.

La organización no es el producto de un diseño acabado, sino que ella es un marco en el que los individuos y los grupos se modifican unos a otros, y recrean la institución. No la determina la racionalidad del diseño sino, fundamentalmente, su dinámica

\section{Una mirada a la institución: su cultura}

A esta concepción sociológica de la institución, le corresponde una investigación naturalista, que pretende comprender y no sólo medir, a través de una búsqueda de corte etnográfico que desplaza la exclusiva mirada positivista, racional, que pretende abordar a la institución desde la razón únicamente; aparece entonces lo subjetivo, se reconocen los valores, las creencias de los individuos y del colectivo. 
Si partimos de esta idea, la cultura del centro educativo aparece como un componente relevante, a considerar tanto como los objetivos, los recursos o la tecnología. Este aspecto es clave para comprender la institución en la que estamos y para generar cambios en la gestión. Y como todo está relacionado, y debe ser coherente en el marco de ese paradigma, a un estilo de gestión institucional le corresponde una concepción de docente, de evaluación, de participación, una acción directiva. Schein, en Gore y Dunlap (1988, pág. 63) ${ }^{1}$, definió la cultura organizacional como:

".. el patrón de supuestos básicos que un grupo dado ha inventado, descubierto o desarrollado en el proceso de aprender a enfrentar problemas de adaptación externa e integración interna, y que han funcionado lo suficientemente bien como para ser considerados válidos, y en consecuencia para ser enseñados a los nuevos miembros como una forma correcta de percibir, pensar y sentir en relación a esos problemas".

La cultura de una institución es representada por algunos autores, como un iceberg, del cual la parte saliente y visible la constituyen los llamados artefactos, indicadores de estratos intermedios y básicos, que sostienen y soportan a esos emergentes.

A los valores los inferimos a partir de lo que dicen los miembros y los documentos de la organización, son aspectos expuestos, manifiestos de una cultura; es en los supuestos donde encontramos los valores reales del grupo, los fundamentos de la conducta. Suelen ser inconscientes y determinan "la forma en que los miembros del grupo perciben, piensan y sienten".

Son estos aspectos claves para realizar un diagnóstico institucional, para "mirar" la institución, y construir "saber reflexivo" sobre ella. No alcanza con conocer las puntas del iceberg, es preciso conocer lo más entrañable de ella, aquello que está en el imaginario colectivo, tanto con relación a lo que es una organización, a cómo se desempeñan los roles dentro de la estructura institucional, y a cómo se relacionan sus integrantes en la interacción.

Creemos que si no se dan verdaderos cambios en dichos aspectos estructurales de la organización, en aspectos sustantivos, como su cultura, no habrá cambio, sólo habrá un vocabulario nuevo, algunos novedosos documentos y tecnologías, pero en un marco referencial incambiado. A continuación consideraremos un aspecto que hace a esta nueva cultura institucional: los conflictos.

\section{Los conflictos}

En toda institución educativa hay conflictos, entre profesores, entre profesores y alumnos, entre alumnos, profesores y padres de alumnos, entre profesores y la dirección, entre padres, entre sectores.

Si bien comienza a prestársele atención a los conflictos, especialmente en el comportamiento organizativo, y algunos lo consideran un "tema clave" de la organización, la situación más común que se da en nuestros centros educativos, es la de una indiferencia hacia la realidad del conflicto, la intranquilidad ante ellos, la pretendida destrucción de quienes los plantean, la confrontación personal de quienes sustentan posiciones o ideas divergentes, especialmente con la Dirección. La explicación de esto, es la manifestación de una ideología dominante, la tecnocrática positivista, que niega y estigmatiza la existencia del conflicto, en el marco de una visión reduccionista y simplificadora de la realidad.

El conflicto no sólo debiera ser reconocido como natural a la organización, sino que sería positivo abordarlo también como un valor, en tanto las posiciones discrepantes pueden y deben generar debate, (debate ausente en general en la docencia, ausencia que desprofesionaliza), y servir de base para la crítica pedagógica, y la articulación de prácticas sociales y educativas liberadoras. El conflicto es considerado en función de la racionalidad educativa desde la que se emiten los juicios. 
Jares $^{2}$ (1991, pág 108), Profesor de Didáctica y Organización escolar de la Facultad de Ciencias de la Educación de la Universidad de la Coruña, España, define al conflicto como:

"...un tipo de situación en la que las personas o grupos sociales buscan o perciben metas opuestas, afirman valores antagónicos o tienen intereses divergentes".

Es un fenómeno de incompatibilidad entre personas o grupos. Para la visión tecnocrática positivista el conflicto es negativo, no deseable, sinónimo de violencia, de disfunción o de patología, y en consecuencia, una situación que es necesario corregir y evitar. El disentir, origen frecuente de conflictos, es considerado como una actitud negativa.

En el plano educativo, en la enseñanza y en los materiales curriculares, el conflicto en general, se presenta como algo negativo, o se soslaya; la visión que transmite el currículo es «aconflictiva» tanto en el plano social como en el científico. No se percibe por parte de los estudiantes el conflicto intelectual y normativo en las áreas temáticas.

En el plano organizativo, las teorías clásicas, omiten la referencia al conflicto, o lo presentan como una desviación, algo disfuncional patológico. Es visto como un indicador de desajustes o insatisfacciones. Desde esta perspectiva, la gestión de la escuela sólo será estable, facilitada y facilitadora, cuando sea posible prever y minimizar los conflictos. Lo que se sugeriría, entonces, sería una intervención previsora y oportuna, a través de una cuidada programación de actividades y de la utilización de los procesos de control para evitarlos, o para anularlos. Un buen director en este sentido es quien demuestra competencia para evitar situaciones conflictivas.

Una característica distintiva de esta racionalidad es el culto a la eficacia en la gestión; la cual se configura como algo objetivo, neutral, técnico y absoluto. La eficacia pasa a ser el objetivo institucional, conviertiéndose en el criterio o referente principal para la toma de decisiones. Se trata de mantener el statu quo, evitar la gestación de los conflictos, y saber limitarlos, reducirlos, eliminarlos; se gestiona el conflicto pero para mantener el control.

Otra característica de esta racionalidad es el papel que juega el conflicto en la relación entre teoría y práctica. Se cree que el conflicto se produce en la práctica por una mala planificación o por una falta de previsión. Por estar la práctica dependiendo de la teoría, los mayores esfuerzos que deben realizar los gestores se centran en la planificación y el control. El conflicto por lo tanto será siempre un problema teórico, frente al cual habrá de tomarse medidas correctoras para resolver "la disfunción" que los prácticos deberán ejecutar, siempre separando hechos de valores. Para esta racionalidad la neutralidad es una obsesión, los conflictos que no pueden controlarse técnicamente, se consideran de naturaleza ideológico política, y por lo tanto no pertinentes a la escuela.

El enfrentamiento positivo de los conflictos puede favorecer los procesos colaborativos de la gestión escolar para que las escuelas como organizaciones sociales se conviertan en un entorno cultural en el que se promuevan valores de comunicación y deliberación social, interdependencia, solidaridad, colegialidad en los procesos de toma de decisiones educativas y desarrollo de la autonomía y capacidad institucional de los centros escolares.

Este reconocimiento no significa que veamos la realidad sesgada permanentemente por los conflictos, y que los mismos sean siempre constructivos. Cuando un conflicto se hace crónico y no se resuelve, deja de tener sus propiedades "vitalizantes" y democráticas para el grupo, pudiendo llegar a ser un elemento desestabilizador del mismo. 


\section{La participación y la evaluación}

Estas ideas reafirman la importancia de la participación como un proceso de construcción de lo nuestro, como una cultura que impregna la concepción que tenemos de la naturaleza humana. Implica un modo de entender las relaciones personales, de enfrentarse a la verdad y de concebirla; un esquema, vital, una manera de percibir y de sentir, de entender y solucionar los problemas y los conflictos.

La participación puede ser vista como técnica para motivar, como un recurso al servicio de la gestión, o como un proceso de aprendizaje, un medio de formación y crecimiento profesional de los docentes. También la evaluación se instala de manera diferente: ¿es una práctica de control, de dominio jerárquico en manos del directivo, o es una práctica de desarrollo humano y profesional del evaluador y del evaluado? Al evaluar a un docente no sólo evaluamos su actuación aislada, sino que evaluamos nuestra gestión, los materiales, los recursos y su administración, la política de formación permanente, entre otros.

El Director aparece en este paradigma como un actor institucional clave, que ocupa un lugar estratégico en la organización. Desde una concepción tecnocrática, normativa, el Director asume una función de planificador y controlador, asociado a una estructura vertical y fuertemente jerarquizada. Nos interesa destacar del directivo, especialmente su liderazgo, esa capacidad de liderar, como persona y como profesional, de animar, de orientar procesos.

Traemos una idea de Beltrán Llavador ${ }^{3}$ : la dirección no puede entenderse sin liderazgo, y nos dice que el concepto de liderazgo ha sufrido también variaciones a lo largo de estos años, pasándose del "liderazgo transaccional" al "liderazgo transformacional". El primero se centra en las tareas, en las transacciones entre líder y seguidores, y el transformacional se orienta a las personas, y consiste en la habilidad del líder para concebir una nueva condición social y comunicar su visión a los seguidores.

Este liderazgo tiene, entre otros rasgos, la capacidad de transformar la dimensión cultural de las organizaciones, está orientado al cambio a través de la participación; el liderazgo no está restringido a una persona, es algo a ser compartido e implica toma de decisiones compartidas. Los cambios, en el marco de esta concepción institucional, que reconoce especialmente el aspecto cultural, no se logran de un momento para el otro. El cambio implica la promoción de nuevos valores y subyacentes básicos, y se centra más en los procesos que en los resultados.

Creo que no será fácil hacer realidad lo que hoy nos planteamos como gestión ideal, si no nos proponemos modificar nuestras ideas básicas y nuestros supuestos más arraigados sobre algunos aspectos. Si esto no ocurre, posiblemente habrá integraciones, novedades superficiales, que solamente podrán generar perjudiciales desajustes y enquistamientos. 


\section{Notas:}

${ }^{1}$ Gore, E. y Dunlap, D. 1988. Aprendizaje y Organización. Una lectura educativa de las Teorías de la Organización. Buenos Aires: Tesis.

${ }^{2}$ Jares, X. 1997. "EI lugar del conflicto en la organización escolar". En Revista Iberoamericana de Educación $\mathrm{N}^{\mathrm{o}}$ 15. Micropolítica en la Escuela.

${ }^{3}$ Beltrán Llavador, F. 1996. "Tradición y Cambio en la Dirección Escolar". En Frigerio, G. y otros. El análisis de la institución educativa. Hilos para tejer proyectos. Buenos Aires: Santillana.

* Magister en Educación. Docente y tutora en el Instituto de Educación, Universidad ORT Uruguay. 